\title{
Fermilab
}

\section{Parametric study for use of stainless steel as a material for thermal shield in PIP2IT transferline at Fermilab}

Tejas Rane

CEC / ICMC 2017 Madison

$12^{\text {th }}$ July 2017 


\section{Introduction}
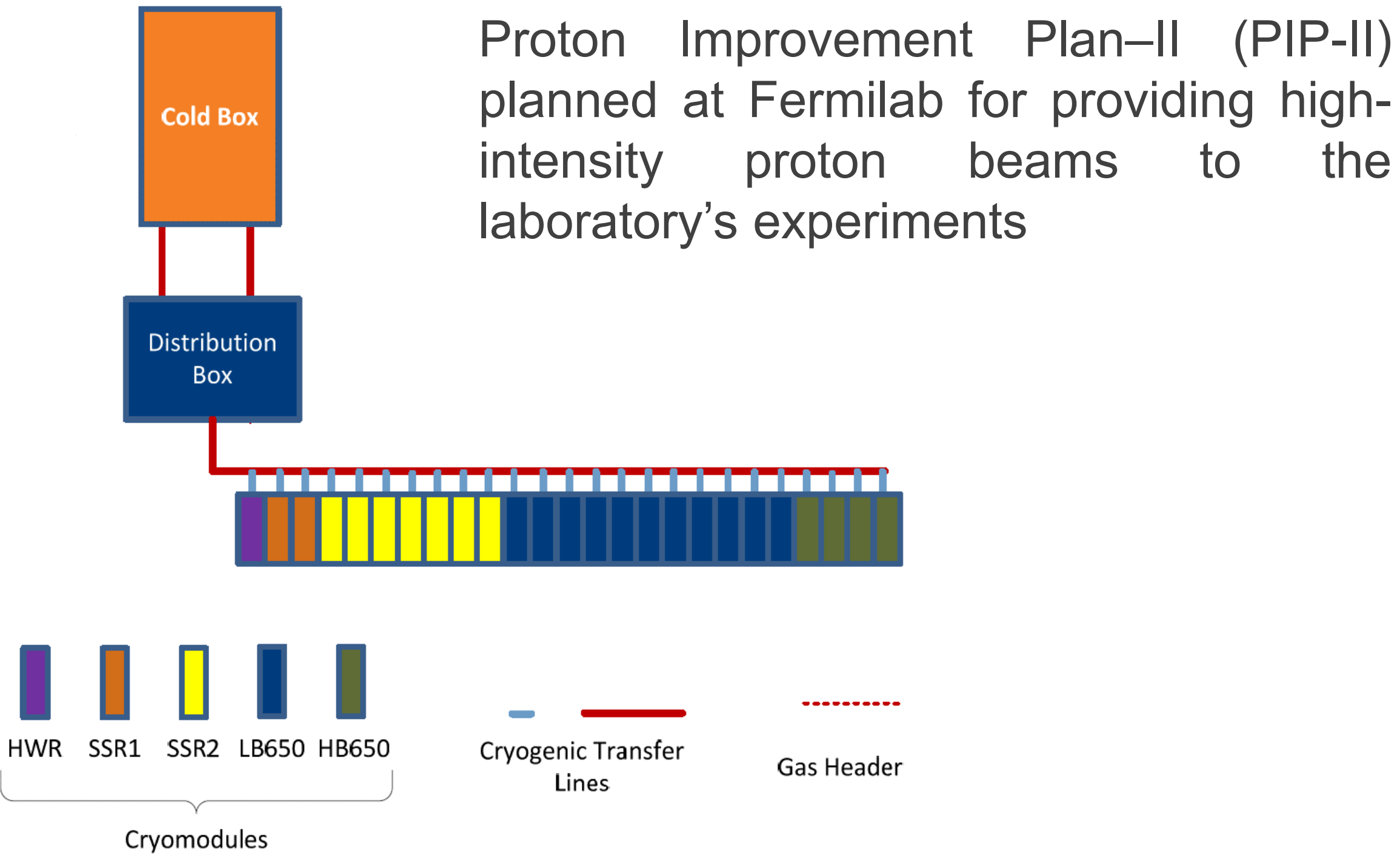

SOURCE: CDR PIP-II FERMILAB 


\section{Introduction}
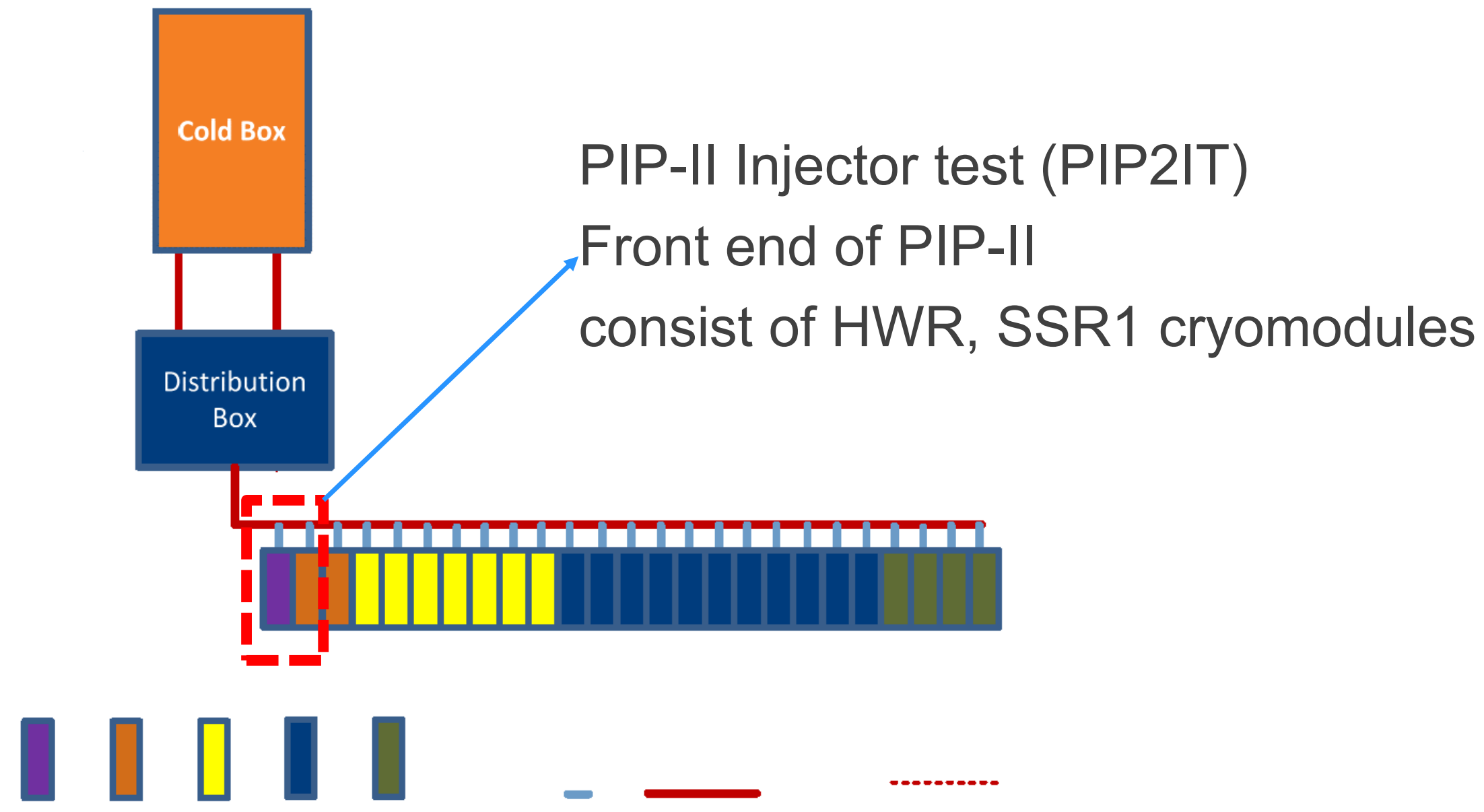

HWR SSR1 SSR2 LB650 HB650

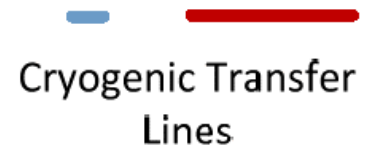

Gas Header

Cryomodules

SOURCE: CDR PIP-II FERMILAB

\section{荤 Fermilab}




\section{Introduction}

PIP2IT tests will be conducted in CMTF building at Fermilab

\section{SCP \\ REFRIGERATOR}

\section{DISTRIBUTION BOX}

PIP2IT TRANSFERLINE

PIP2IT CAVE 


\section{Introduction}

Present paper is related to the thermal shield of the PIP2IT external transferline

\section{SCP}

REFRIGERATOR

PIP2IT - EXTERNAL TRANSFERLINE

\section{DISTRIBUTION BOX}




\section{Introduction}

\section{Sectional view of part of the PIP2IT transferline}

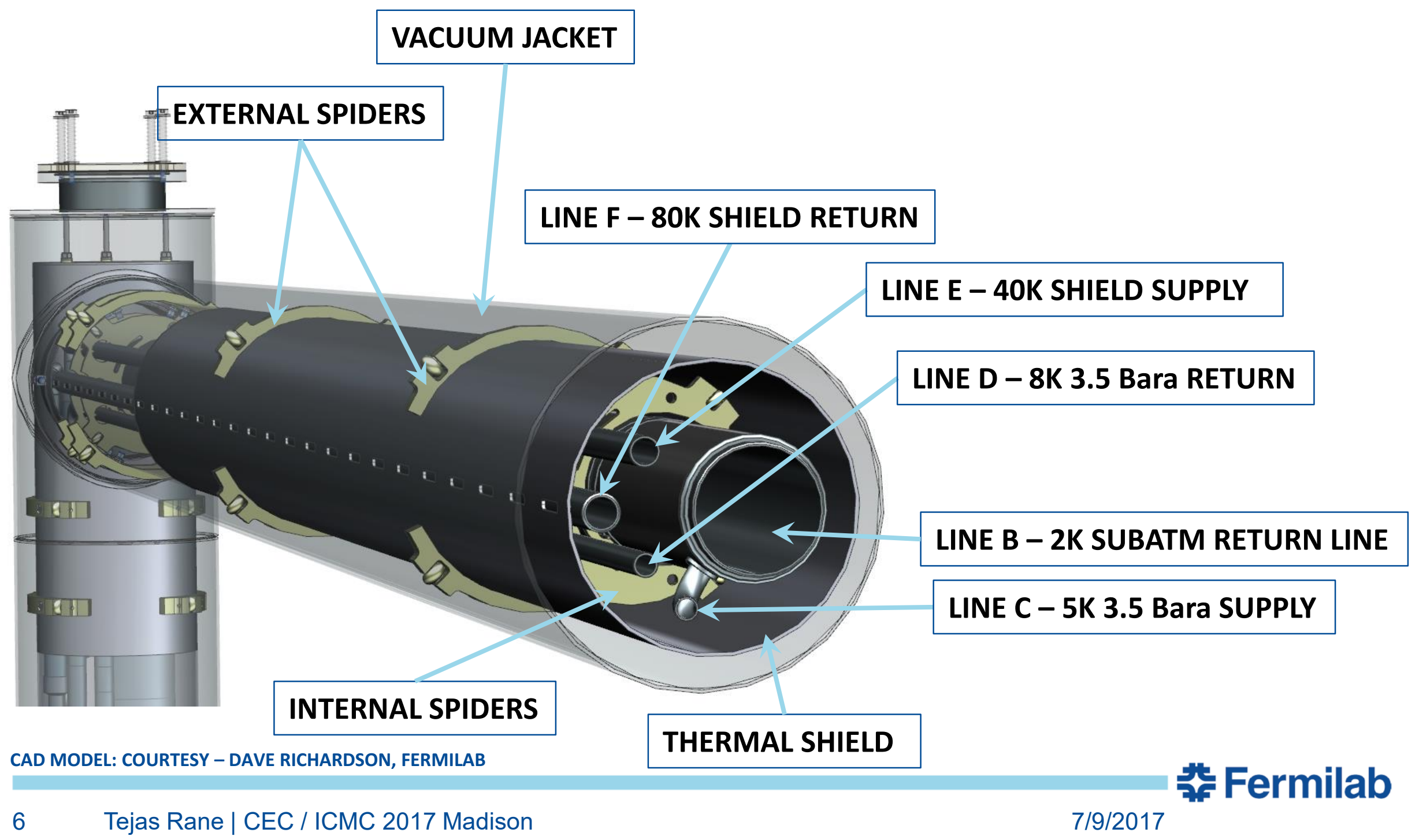




\section{Problem Description}

Copper or Aluminium are preferred materials for the thermal shield because of higher thermal diffusivity

However, stainless steel has been selected for fabrication of PIP2IT thermal shield due to following advantages-

- Easy availability of seam welded 10inch OD tube

- Reduced cost as compared to copper or Aluminium shield

- Higher strength of SS

- Welding Stainless steel (SS) shield to SS pipe is easier than brazing of Copper/Aluminium to SS 


\section{Problem Description}

During cooldown, large thermal gradients occur on the surface of the thermal shield, due to low thermal diffusivity

This gives rise to thermal stresses and strains

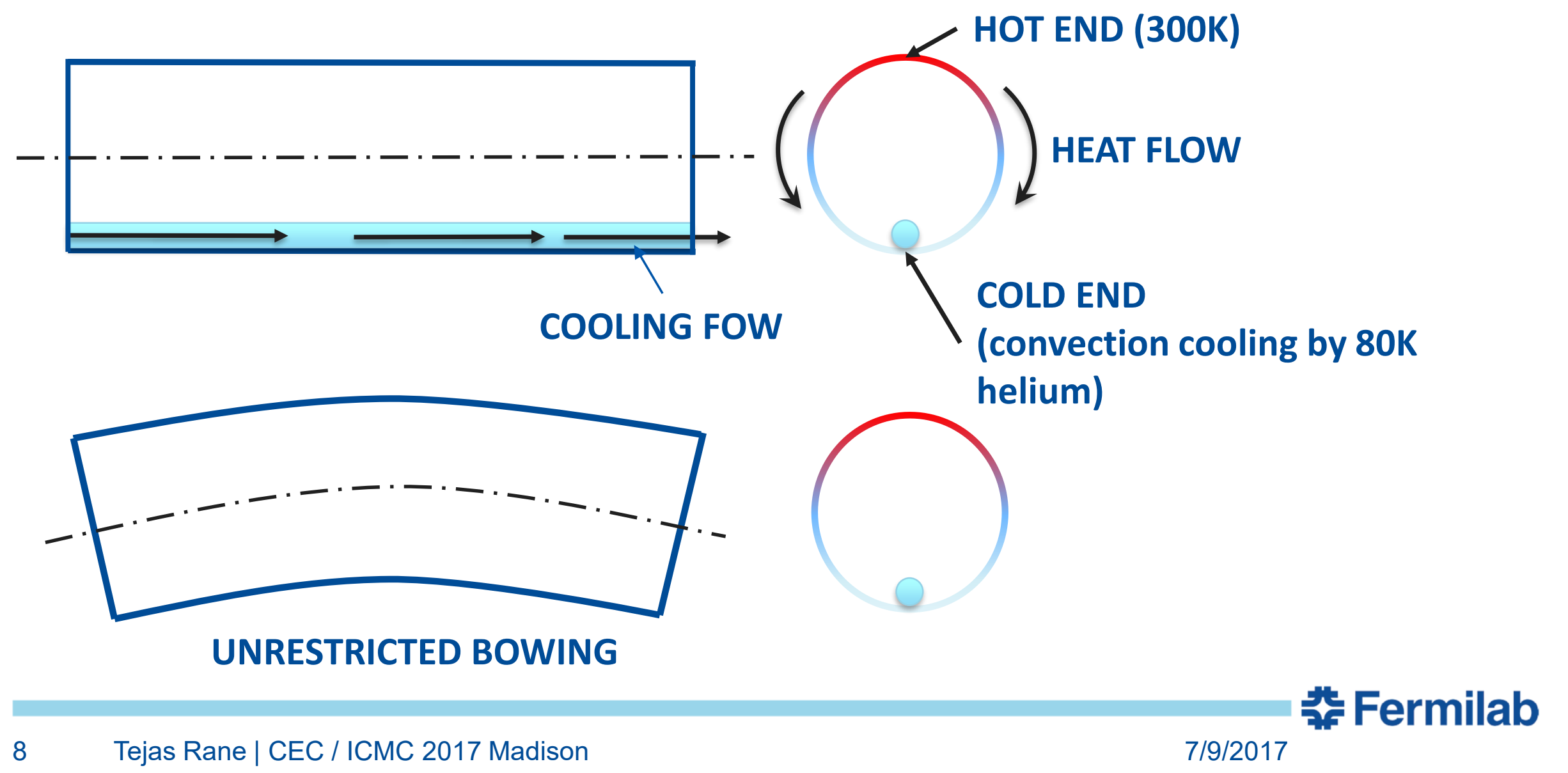




\section{Problem Description}

Stresses are induced because of following two reasons--

1. Hot part of the shield resists the contraction of the cold part (Thermal stresses)

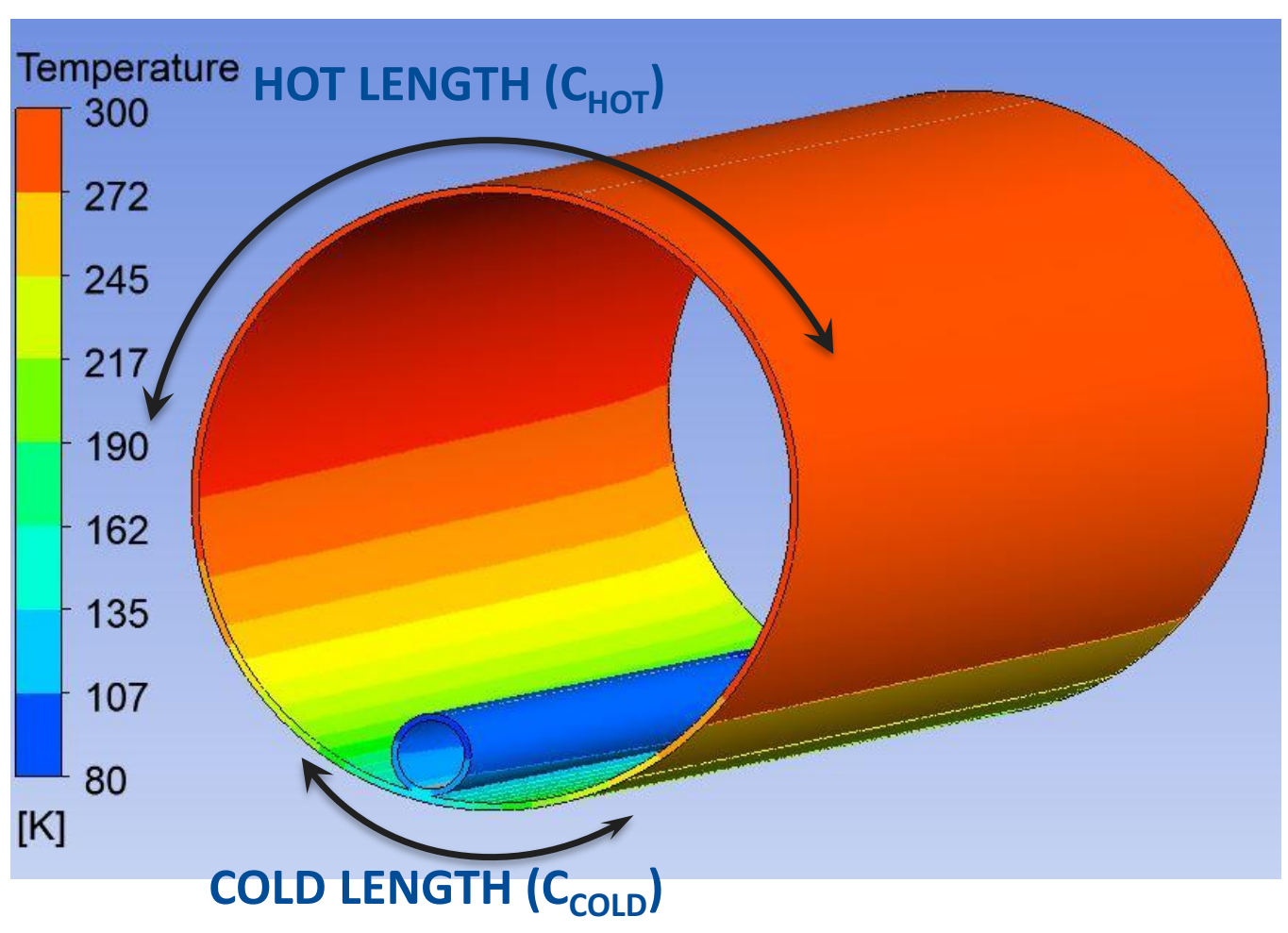




\section{Problem Description}

Stresses are induced because of following two reasons--

2. The vacuum jacket and the Line F prevent bowing deflection of the shield sections (bowing stresses)
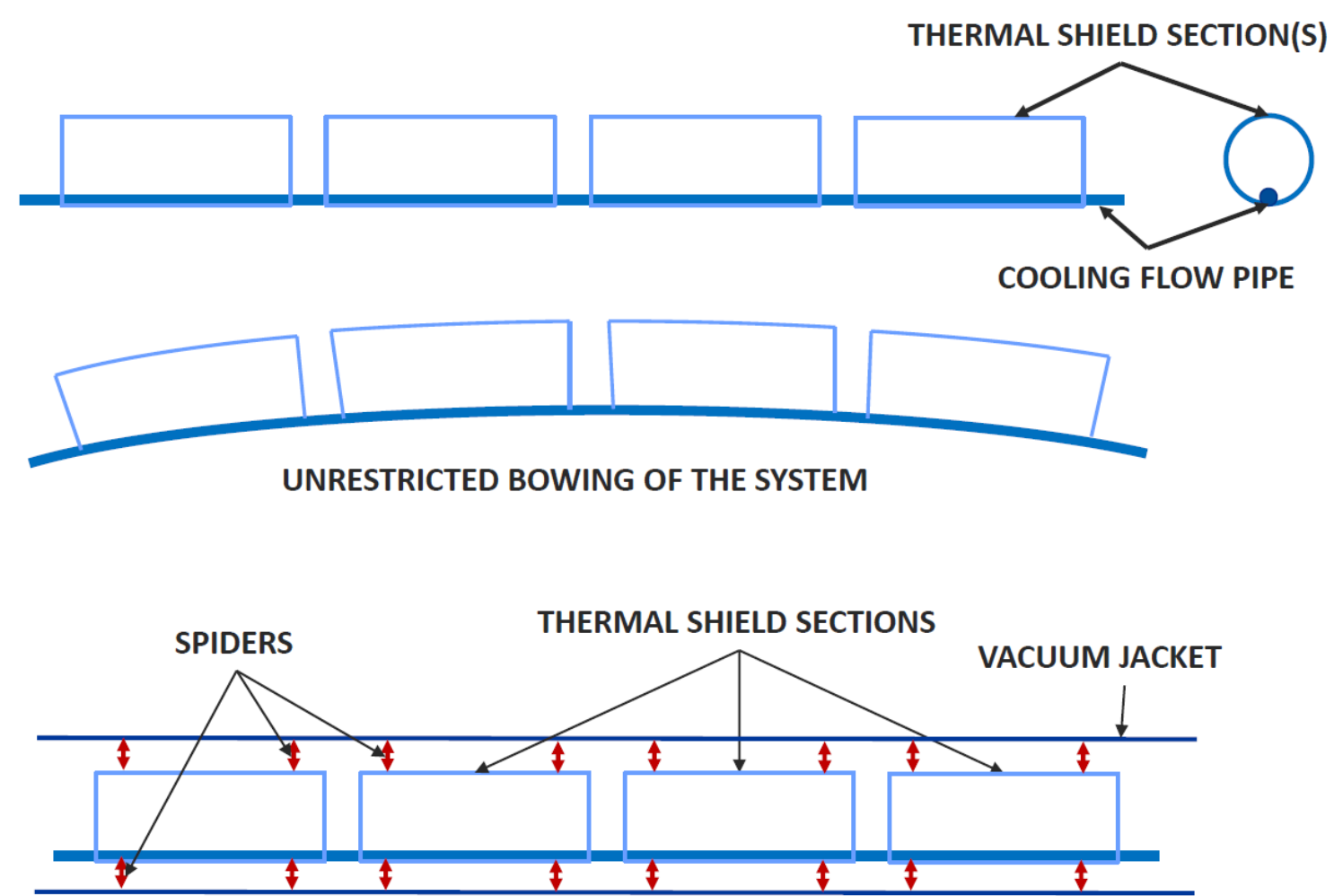

RESTRICTION DUE TO VACUUM JACKET 


\section{Objective and Procedure}

If the length of the shield section decreases, the thermal strains decrease, thus reducing the stresses

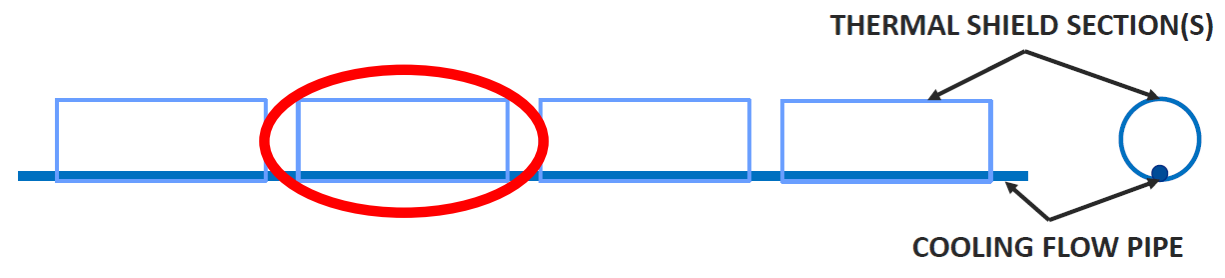

Geometric model of fixed diameter and thickness and variable length

\section{Apply supports and load}
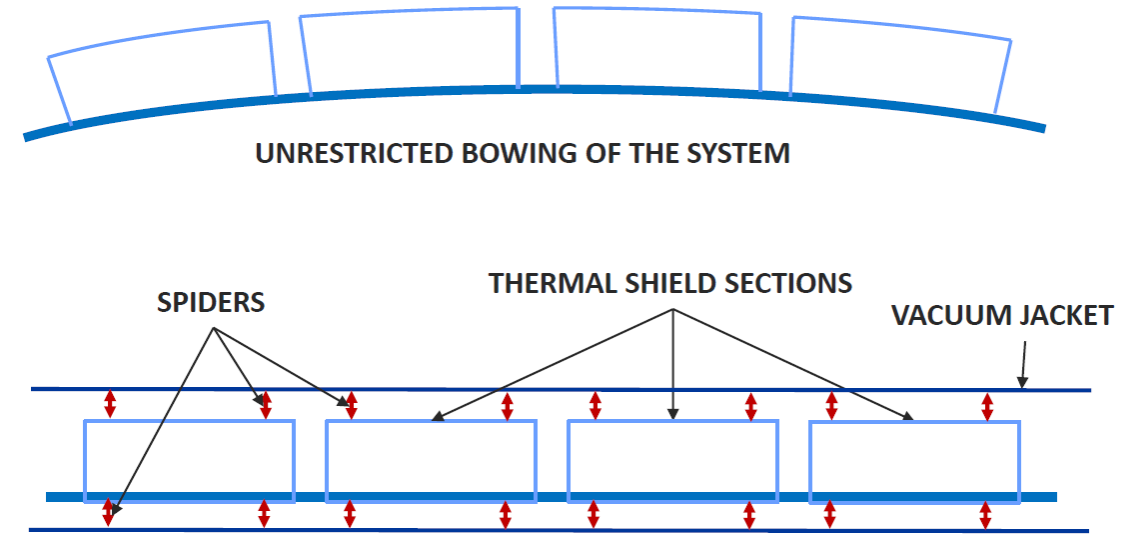

RESTRICTION DUE TO VACUUM JACKET

For diameters 6" to 16",

Vary length to arrive at thickness $3 \mathrm{~mm}, 5 \mathrm{~mm}$ allowable value for safe stresses 


\section{Modeling of the problem-Supports}

1. Support conditions:

- Forces F1, F2, V1, V2 and moments M1, M2 do not allow bowing deflection

(F1, F2 - forces exerted by the vacuum jacket)

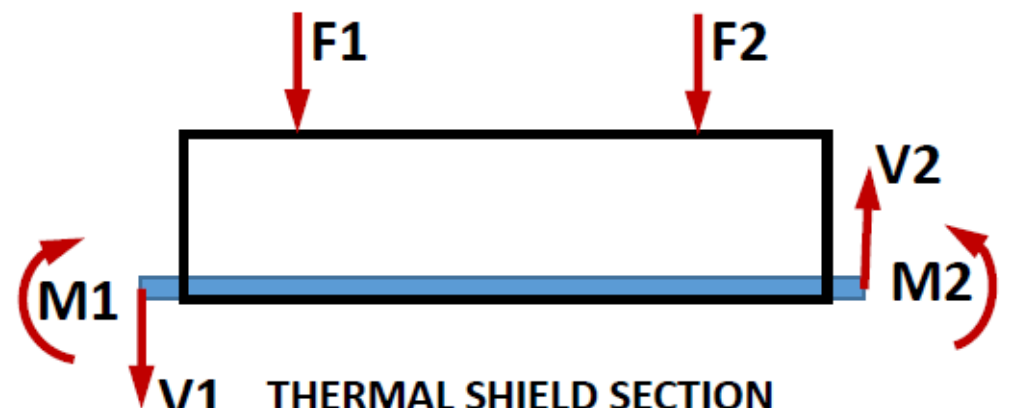

(M1, M2, V1 and V2 are the end reactions)

Support conditions: Approximated

Pure bending with symmetrical frictionless roller supports

(M0 is moment reaction due to supports)

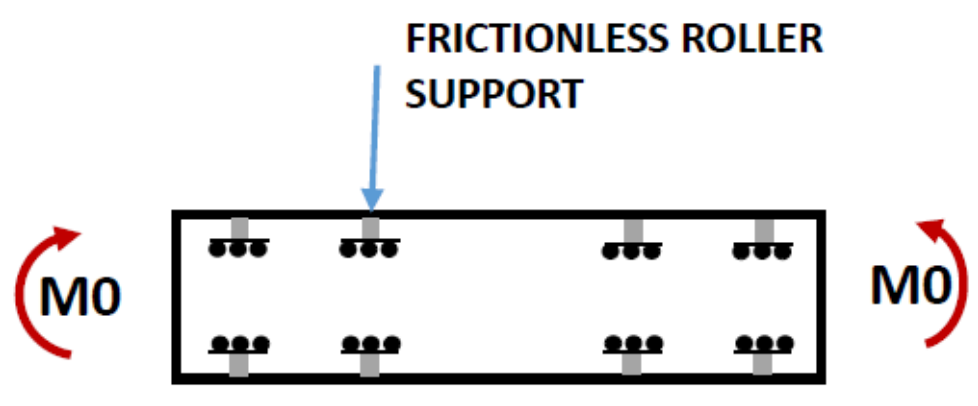




\section{Modeling of the problem-Load}

2. Load (temperature distribution)

- Temperature distribution in case of transient cooldown problem

- $\phi 10 "$ shield section, $10 \mathrm{ft}$ long

- $10 \mathrm{~g} / \mathrm{s}$ helium flow at $12 \mathrm{bara}, 80 \mathrm{~K}$

Load (APPROXIMATED)

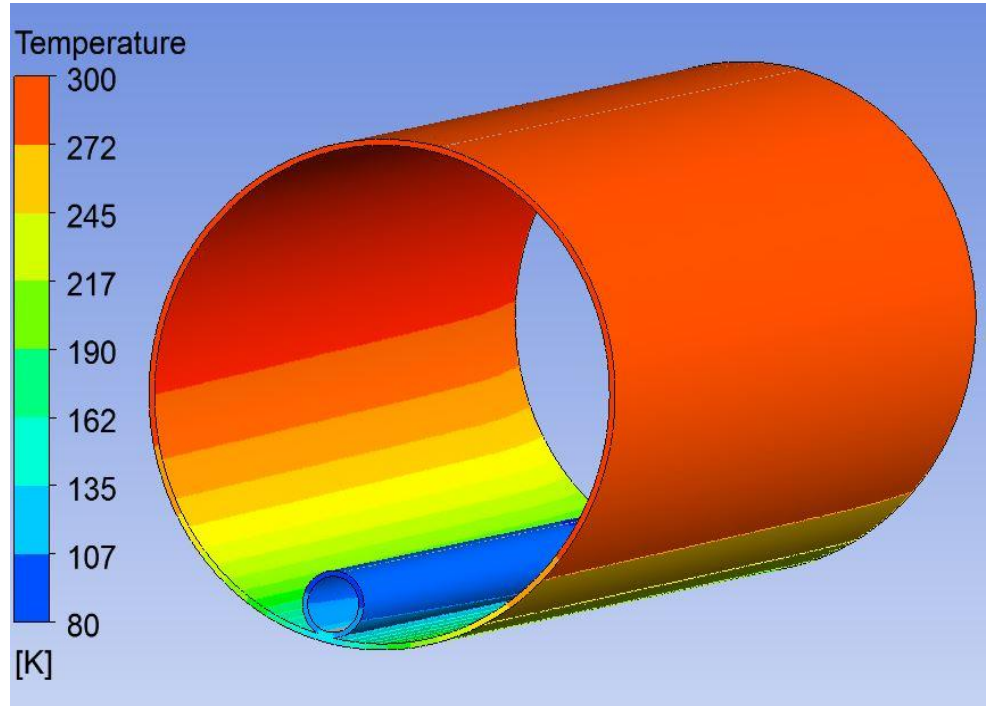

Approximated as steady state distribution
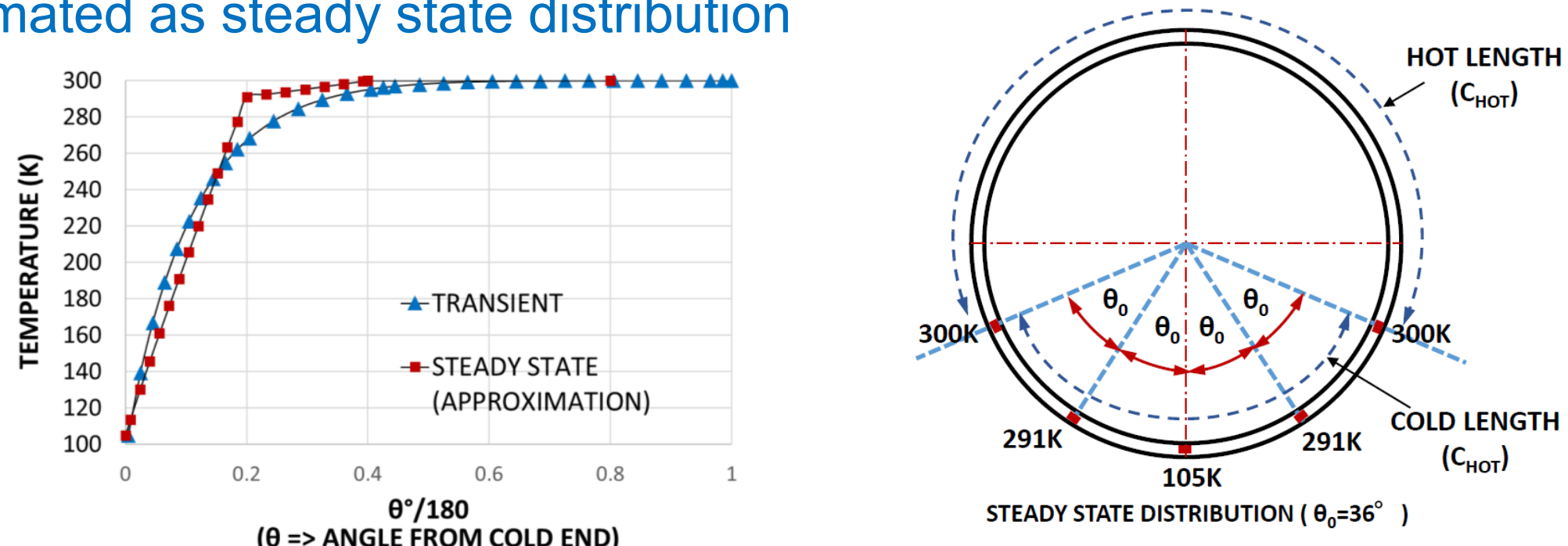

STEADY STATE DISTRIBUTION $\left(\theta_{0}=36^{\circ}\right)$ 


\section{Assumptions}

Key Assumptions:-

- $10 \mathrm{~g} / \mathrm{s}$ of helium, at $12 \mathrm{bar}$ and $80 \mathrm{~K}$, through Line $\mathrm{F}$ is considered as the maximum possible cooling flow

- Temperature is constant along thickness

- The thermal strains incident on the thermal shield do not have nature of a cyclic load. Hence, these are considered as primary loads for evaluation of safe stresses 


\section{Results and discussions}

The allowable lengths (Ls) of the thermal shield sections are plotted for different diameter values on X-axis for thickness $3 \mathrm{~mm}$ and $5 \mathrm{~mm}$ as shown in the figure

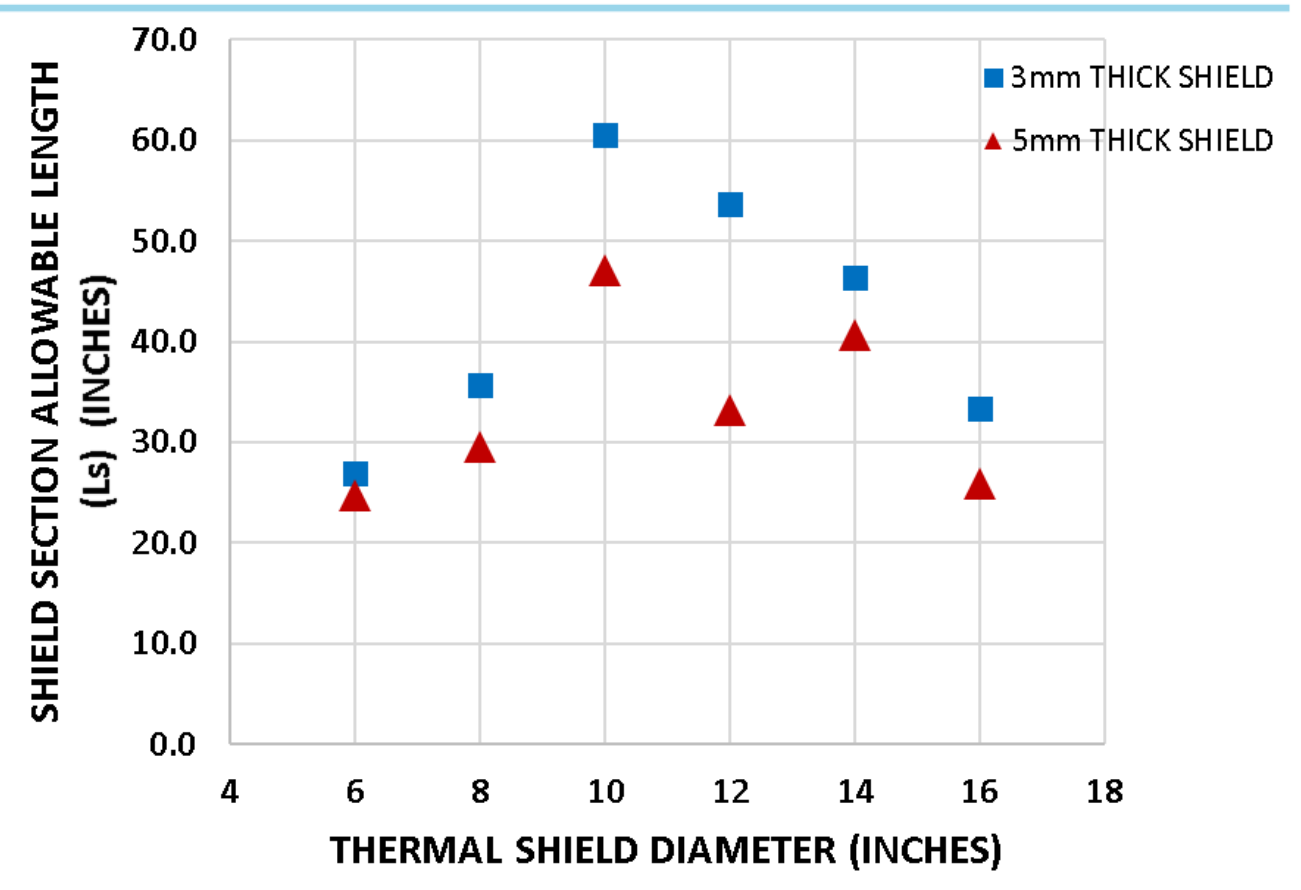

Criteria for allowable stress

$P_{l}+P_{b} \leq S_{p l}$

$P_{l}=$ Primary local membrane stress

$P_{b}=$ Primary local bending stress

$S_{p l}=$ Allowable stress value

$S_{p l}=$ Yield stress $\left(S_{y}\right)$ forStainless steel $\left(2.07 \times 10^{8} \mathrm{~N} / \mathrm{m}^{2}\right)$ 


\section{Results and discussions}

- Flexibility decreases with increase in diameter

- Flexibility decreases with increase in thickness

- As diameter increases the hot length increases. however the angle $\theta_{0}$ is not modified for smaller diameters - hence

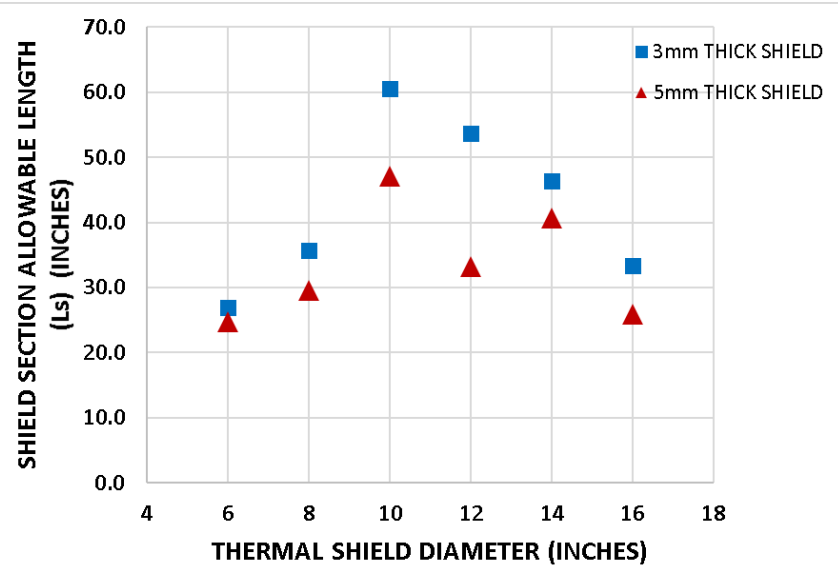
conservative loads due to higher thermal gradients

Safe lengths can be selected for equal or lower thickness from the data points without rigorous analysis

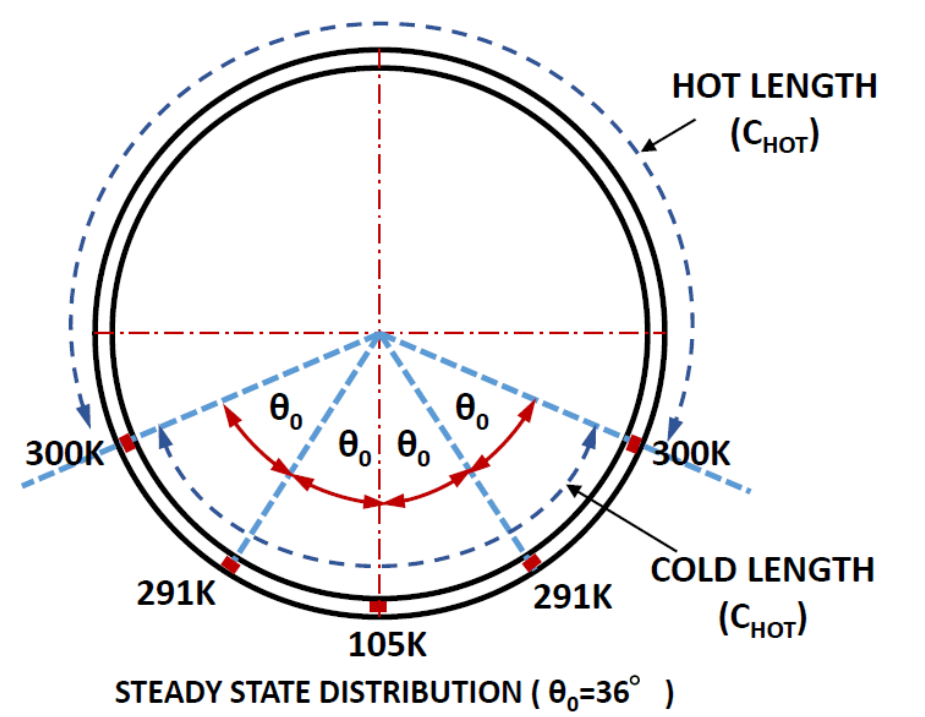




\section{Thank you for your attention}



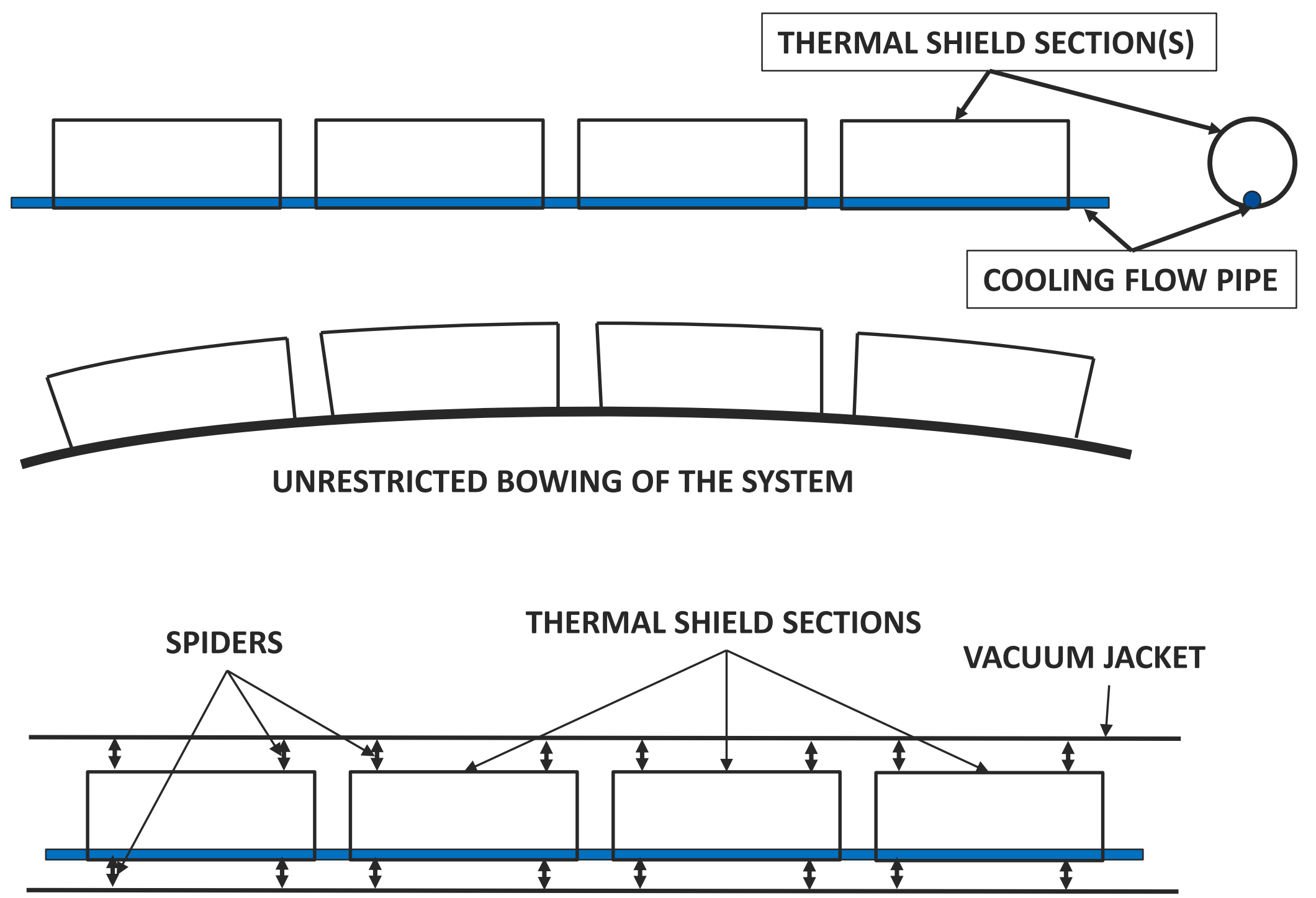

RESTRICTION DUE TO VACUUM JACKET 


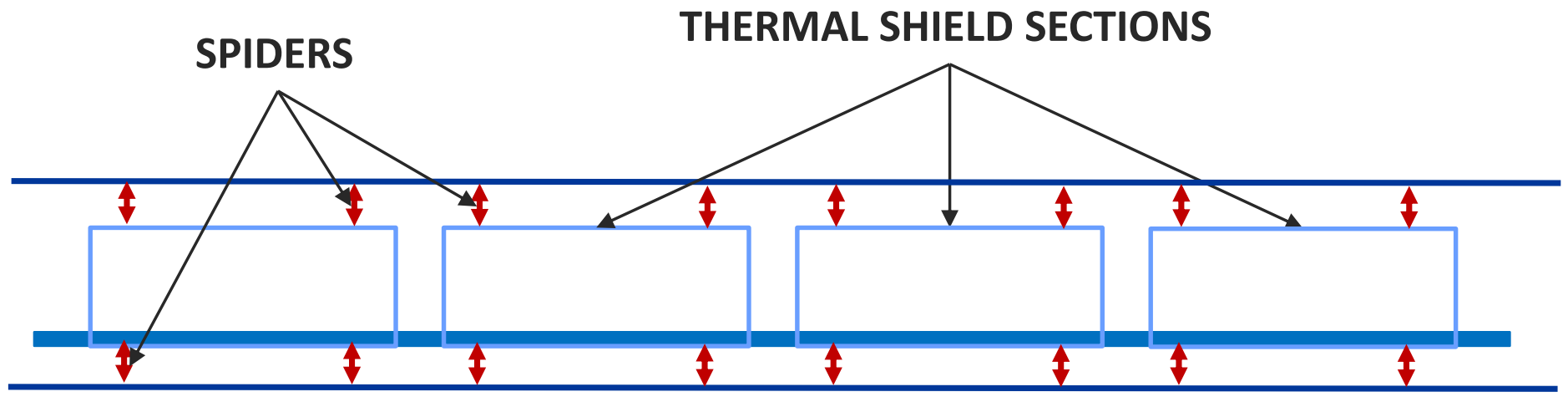

RESTRICTION DUE TO VACUUM JACKET 


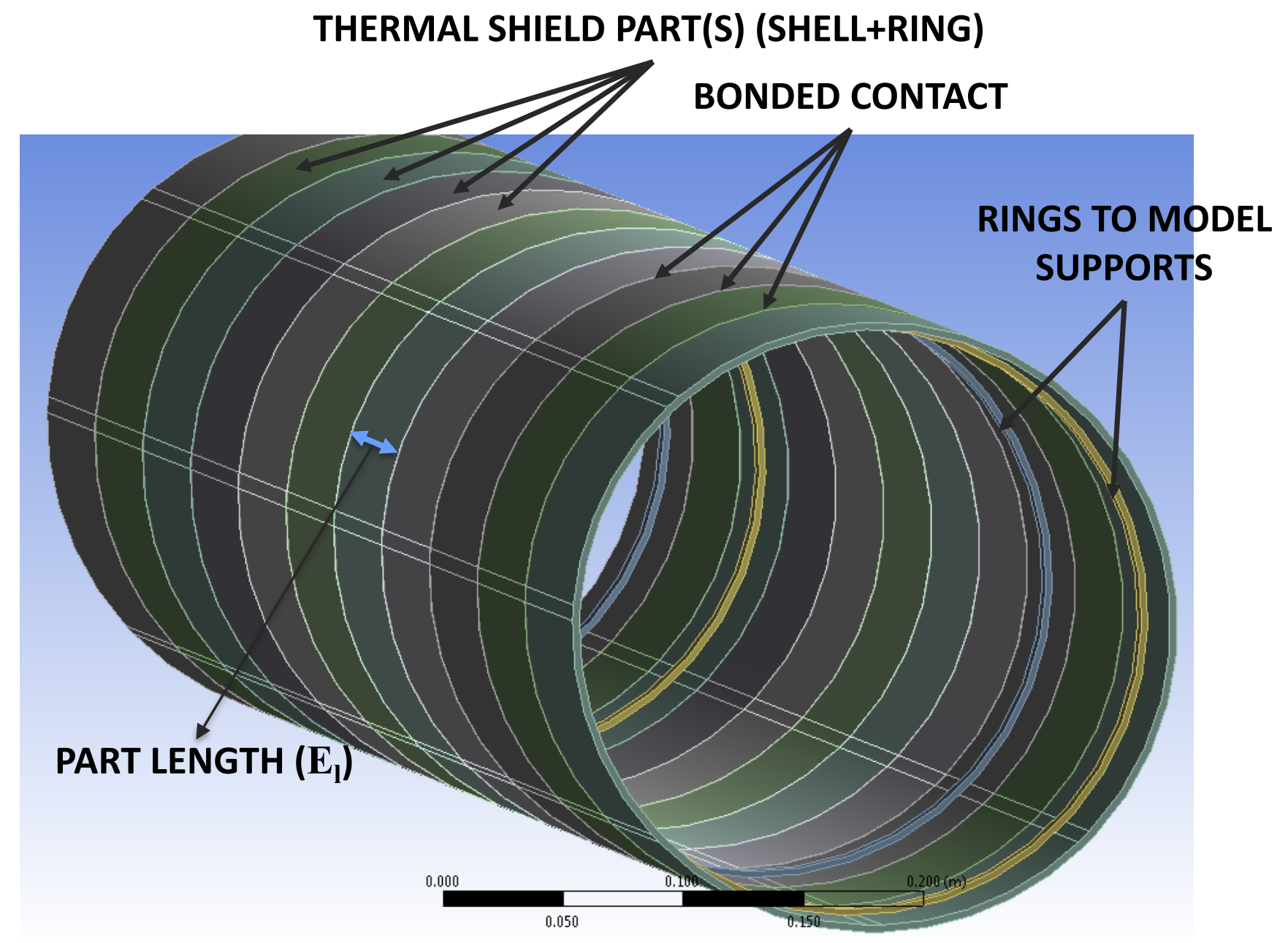

GEOMETRIC MODEL OF THERMAL SHIELD FOR STRUCTURAL ANALYSIS (UNWANTED RINGS AND PARTS SUPPRESSED) 


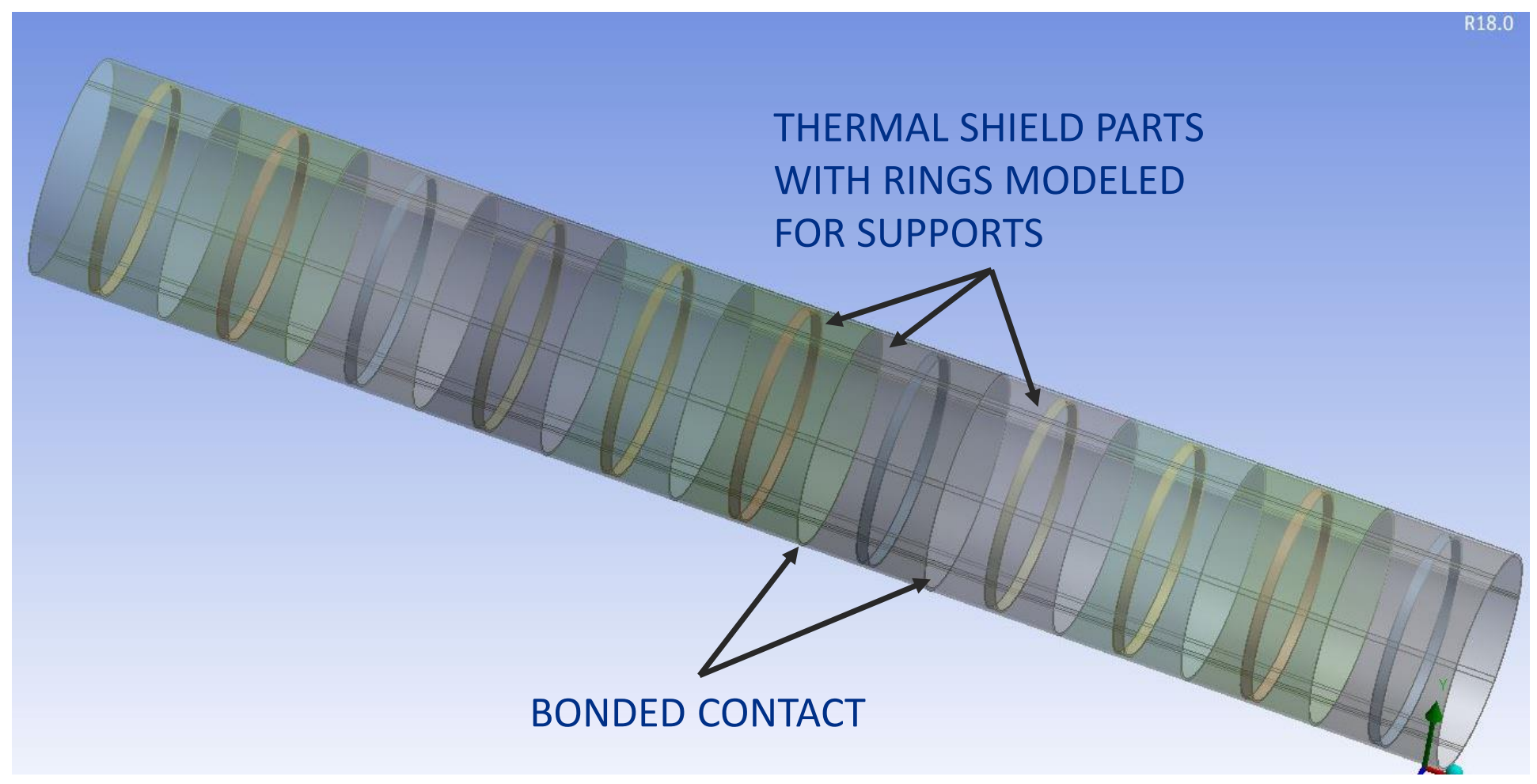

GEOMETRIC MODEL FOR THERMAL SHIELD ANALYSIS 


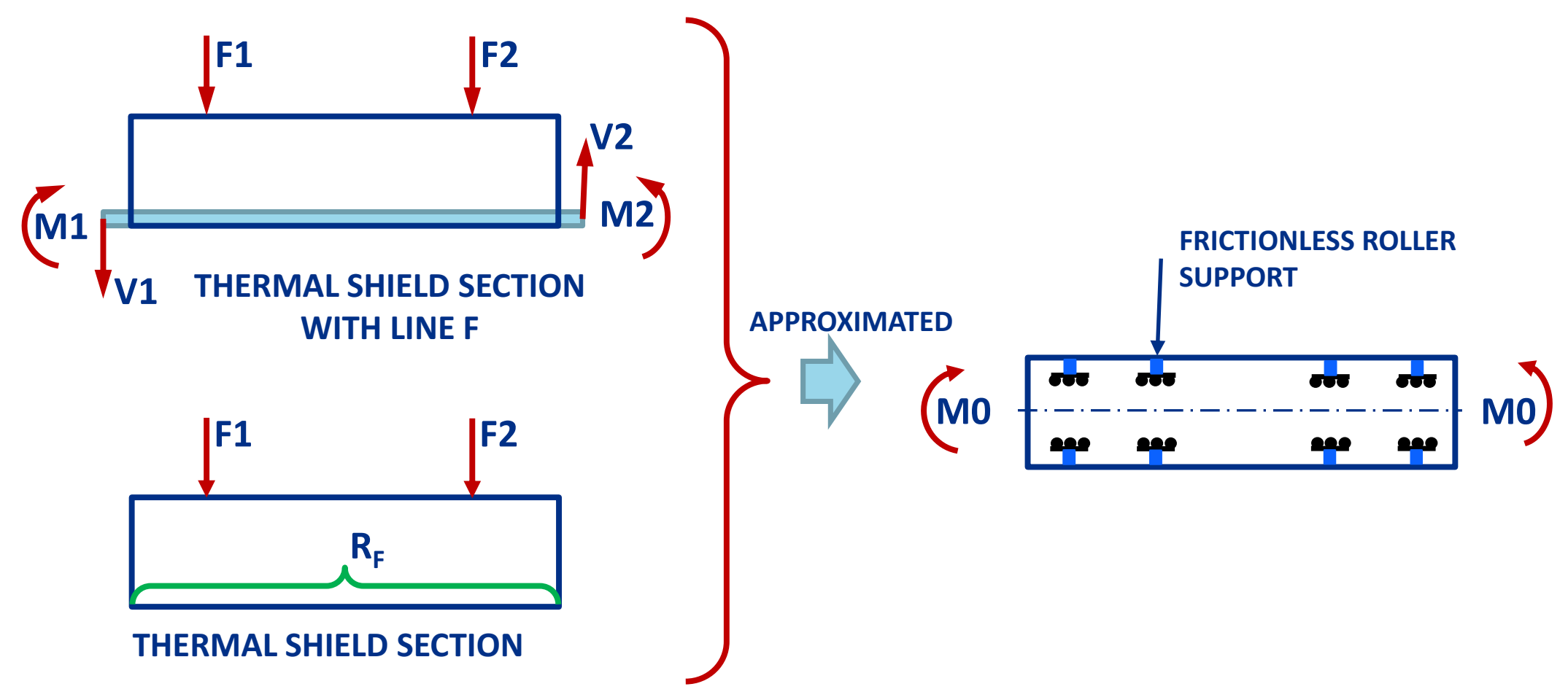

FREE BODY DIAGRAM FOR THE THERMAL SHIELD AND 

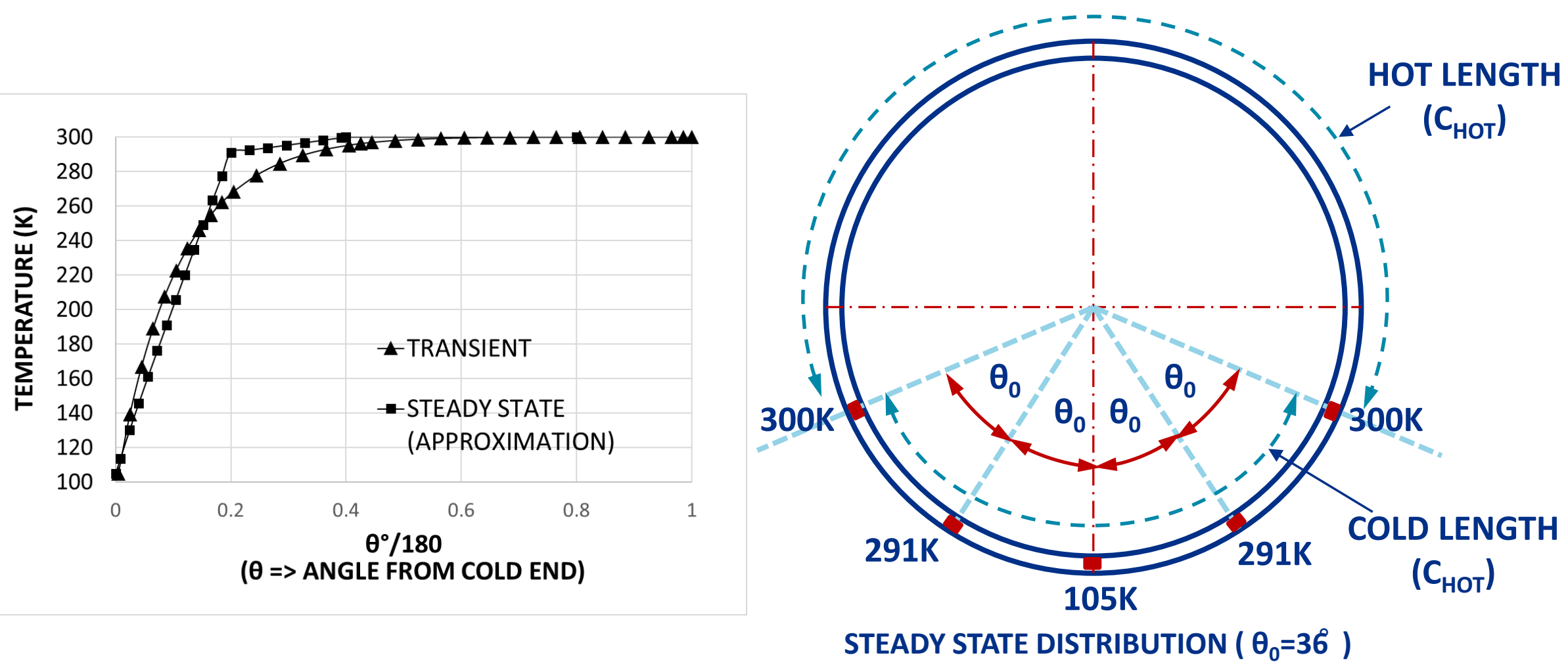